\title{
Insights into Design of Biomimetic Glycerol-Grafted Polyol- Based Polymers for Ice Nucleation/Recrystallization Inhibition and Thermal Hysteresis Activity
}

\author{
Mohammad Mousazadehkasin and John G. Tsavalas*
}

Department of Chemistry, University of New Hampshire, Durham, New Hampshire 03824, USA

*E-mail: john.tsavalas@unh.edu,_ORCID JGT: 0000-0003-4955-9991 
PVA functionalization with Glycidol.
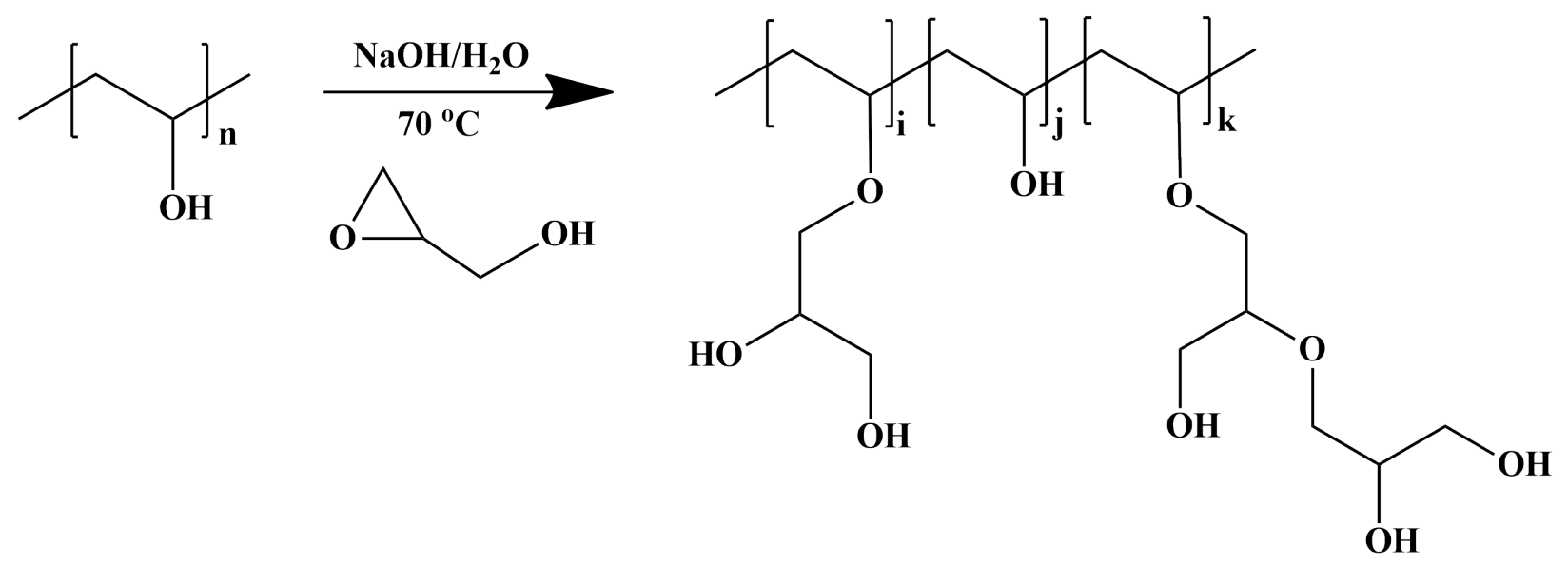

Scheme S1. Synthetic pathway for G-g-PVA.

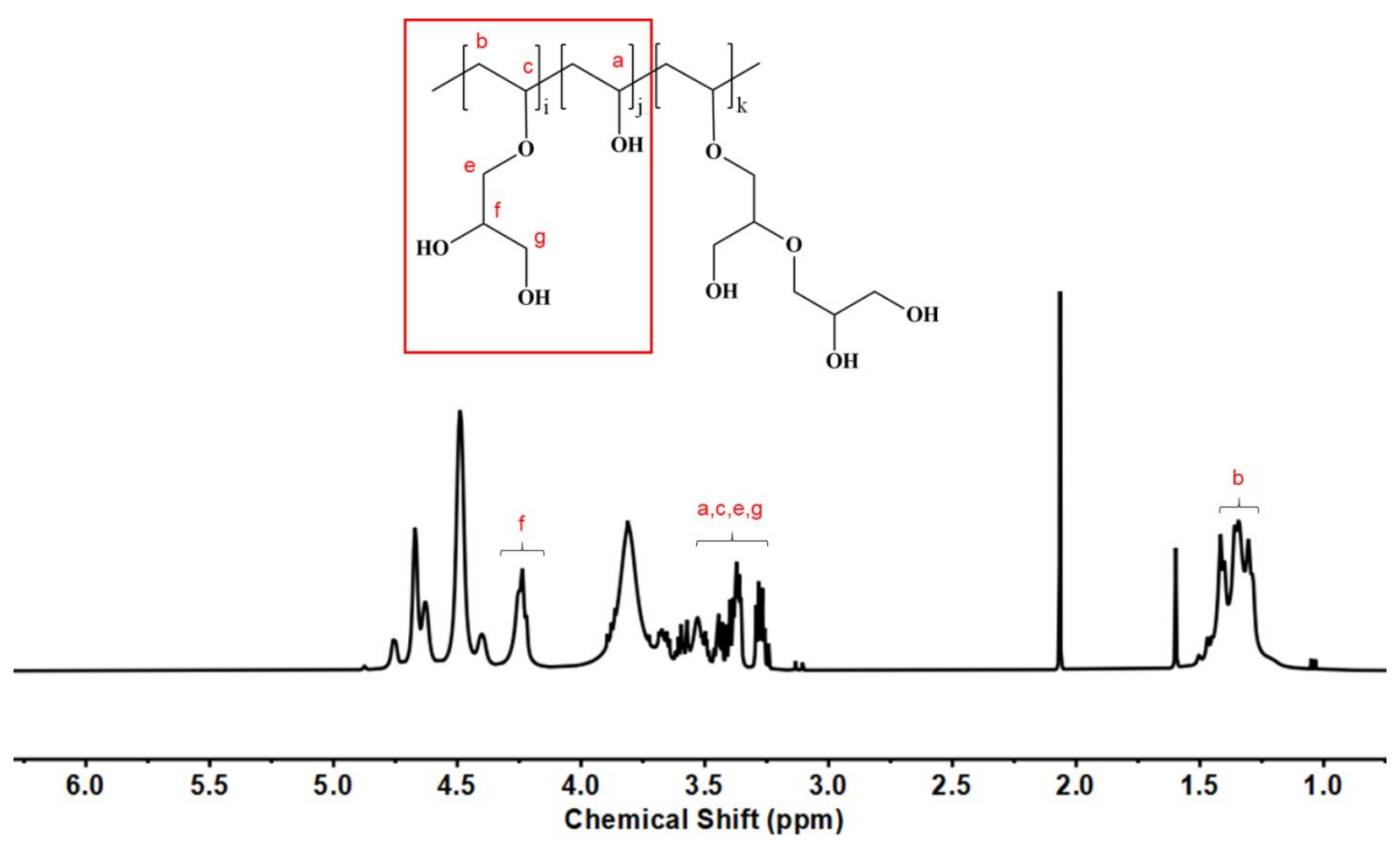

Figure S1. ${ }^{1} \mathrm{H}$ NMR spectra recorded in $\mathrm{d}_{6}$-DMSO for G-g-PVA. 


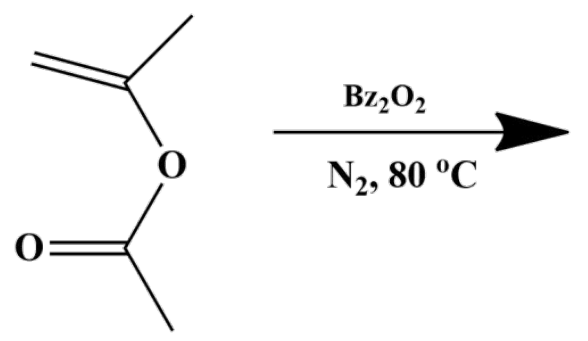

Isopropenyl acetate IPAc<smiles>CC(=O)OC(C)(C)CC(C)(C)C</smiles>

Poly(isopropenyl acetate) PIPAc

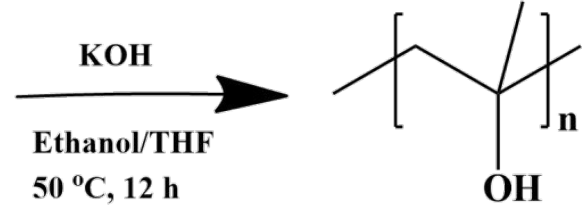

Poly(isopropenyl alcohol) $\mathrm{PIPOH}$<smiles>CC(C)(C)CC(C)(C)C</smiles><smiles>CCOCCOCC1CO1</smiles><smiles>COC(CO)COC(C)(C)CC(C)(C)CC(C)(O)CC(C)(C)C(C)(C)OCC(O)CO</smiles><smiles>O=CC(O)CO</smiles>

Scheme S2. Reaction sequence for the synthesis of G-g-PIPOH. 


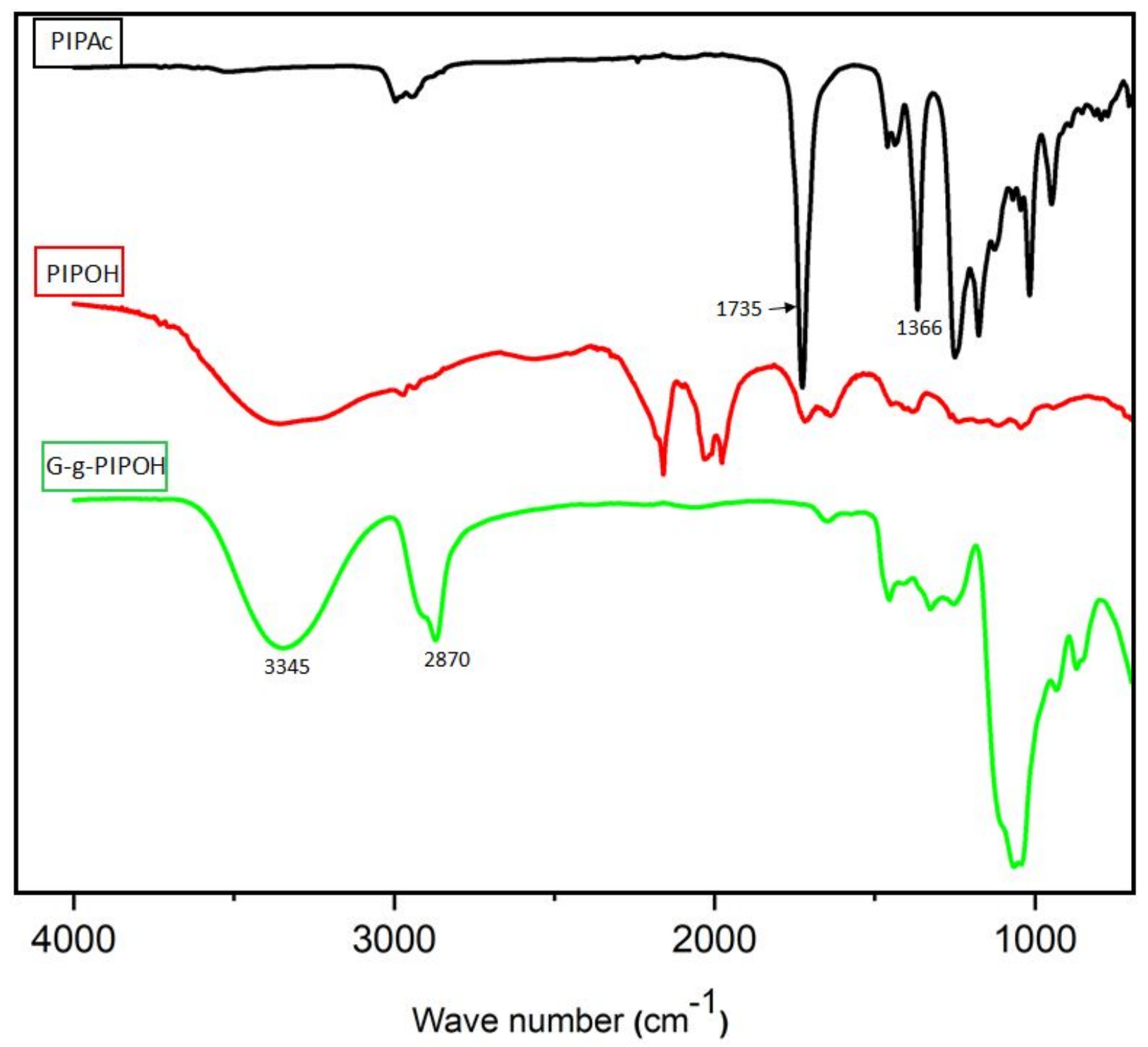

Figure S2. FTIR spectra of PIPAc, PIPOH, and G-g-PIPOH 

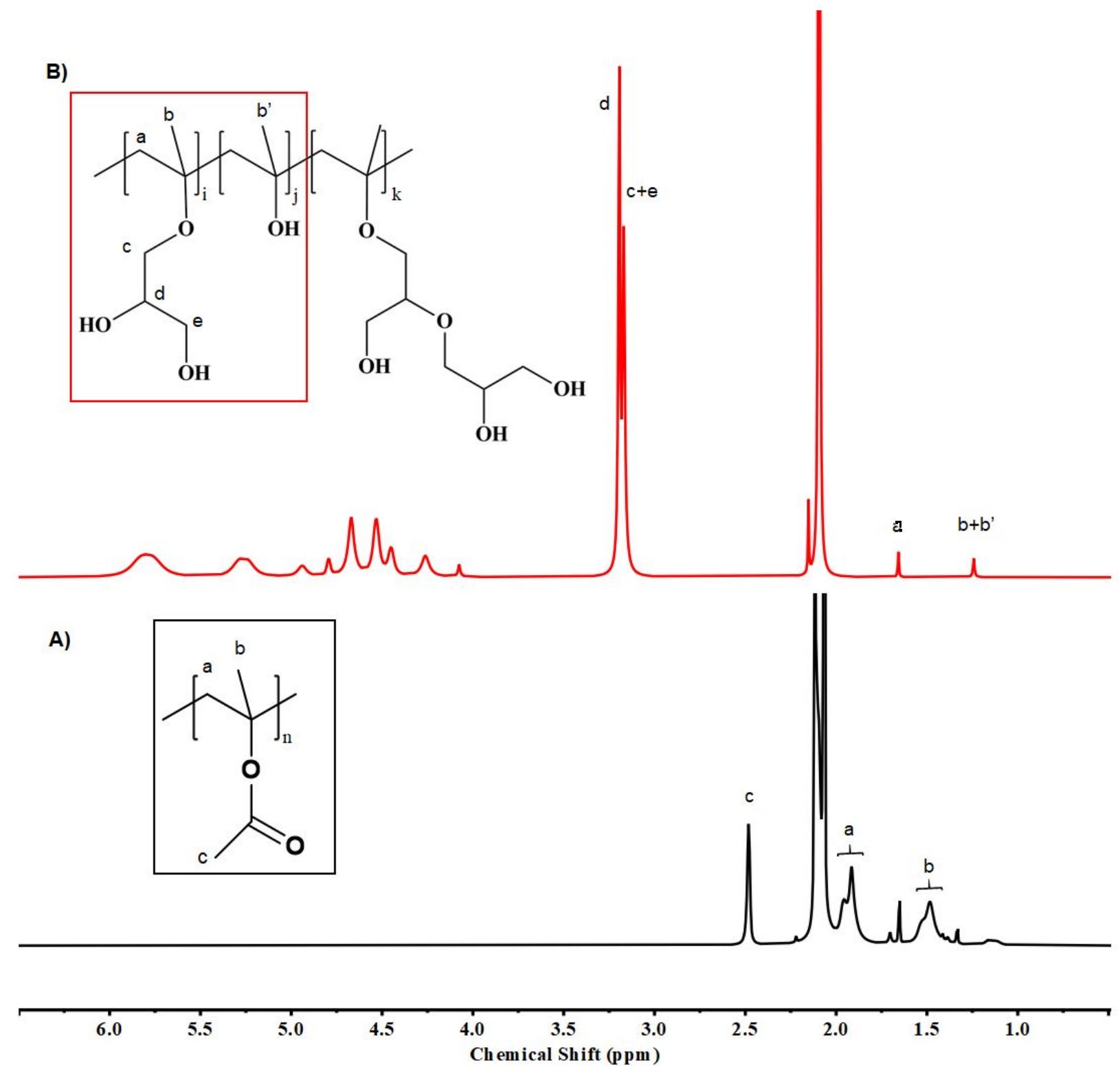

Figure S3. ${ }^{1} \mathrm{H}$ NMR spectra recorded in $\mathrm{d}_{6}$-DMSO for (A) PIPAc and (B) G-g-PIPOH 


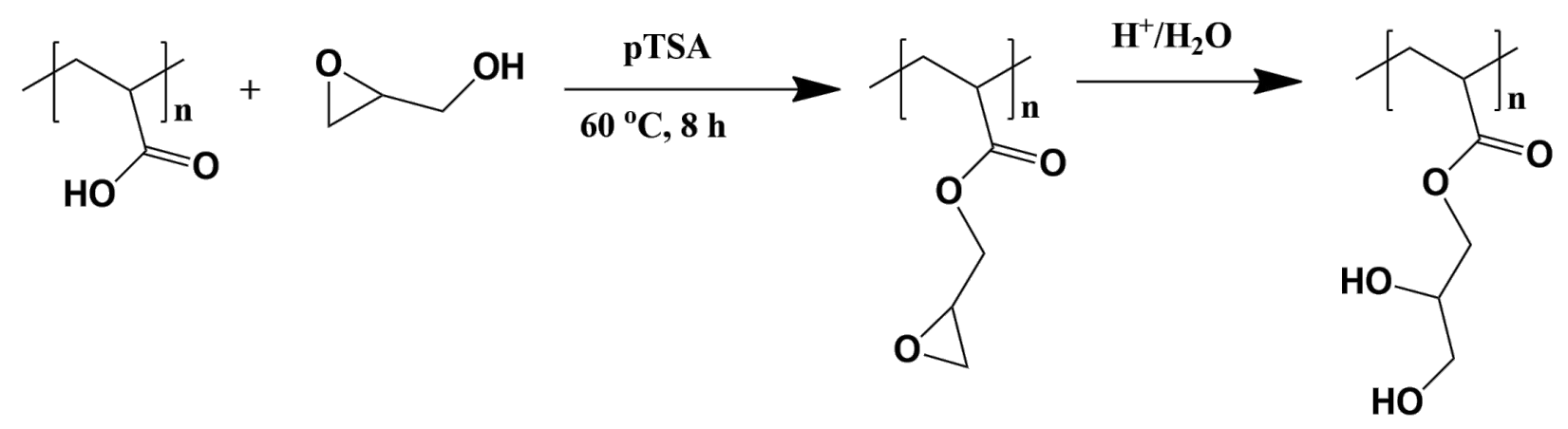

Scheme S3. Synthetic pathway for modification of PAA with glycidol. 

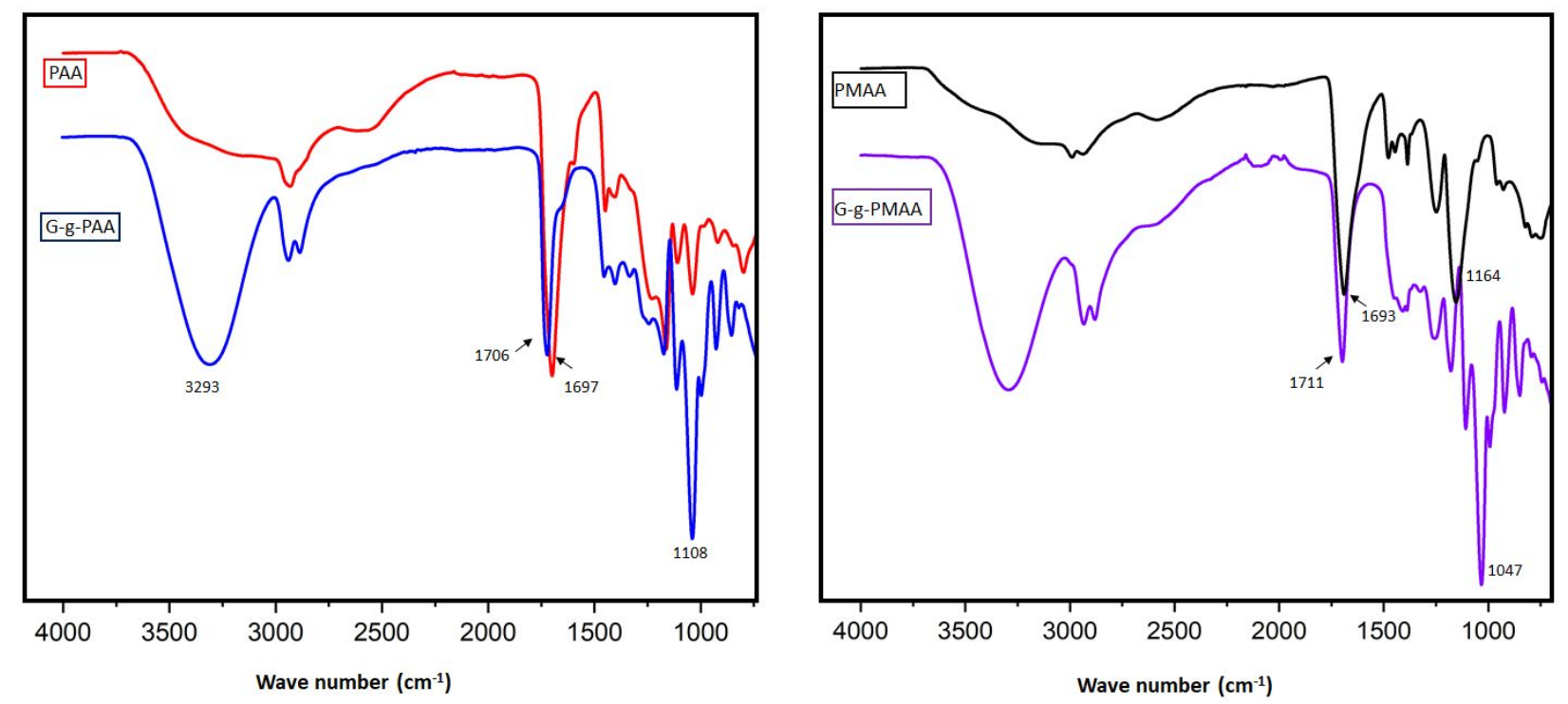

Figure S4. FTIR of PAA vs G-g-PAA (left) and PMAA vs G-g-PMAA (right)

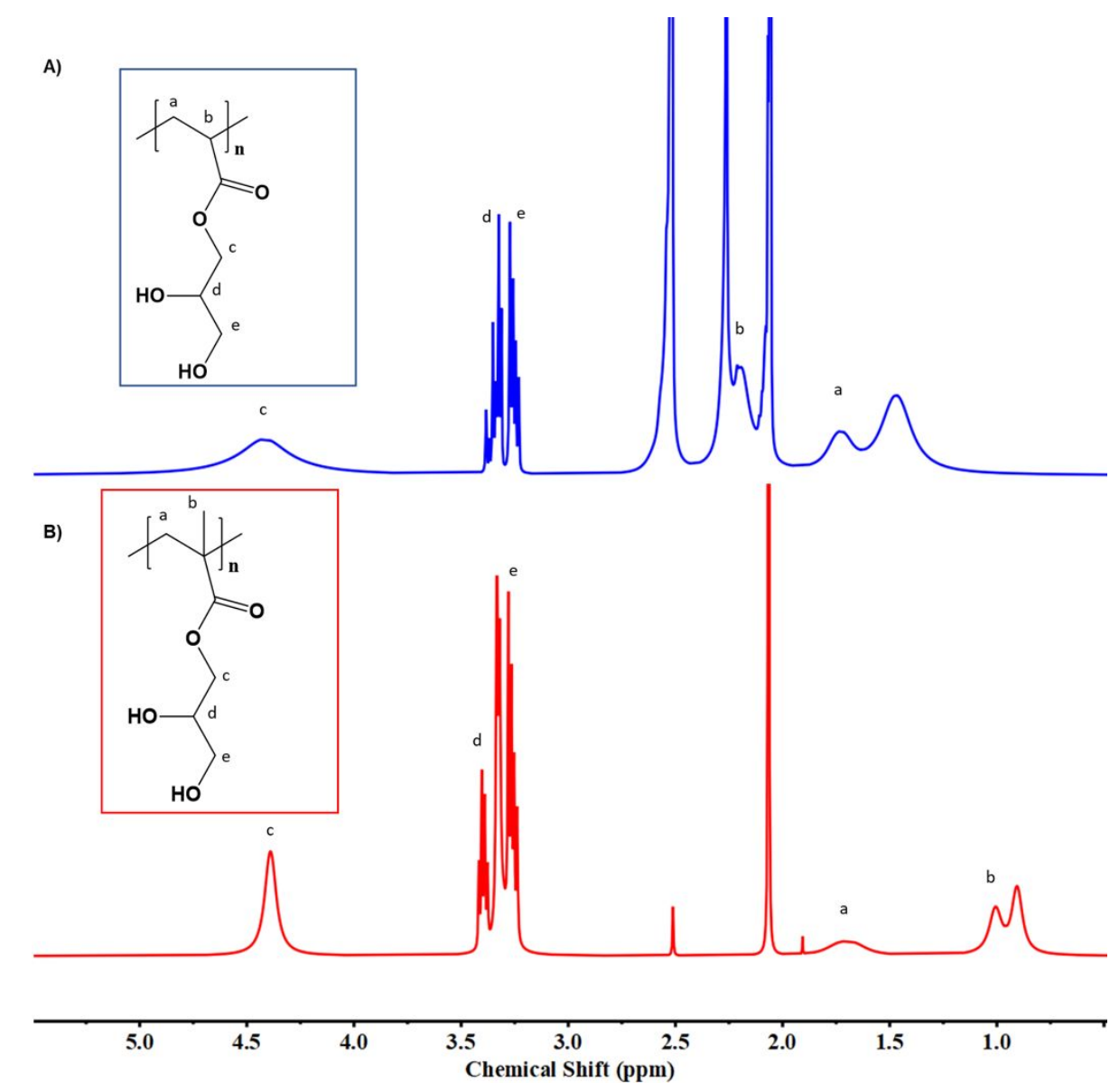

Figure S5. ${ }^{1} \mathrm{H}$ NMR spectra recorded in $\mathrm{d}_{6}$-DMSO for (a) G-g-PAA and (b) G-g-PMAA 


\section{Additional Data on Ice Nucleation Inhibition (INI)}

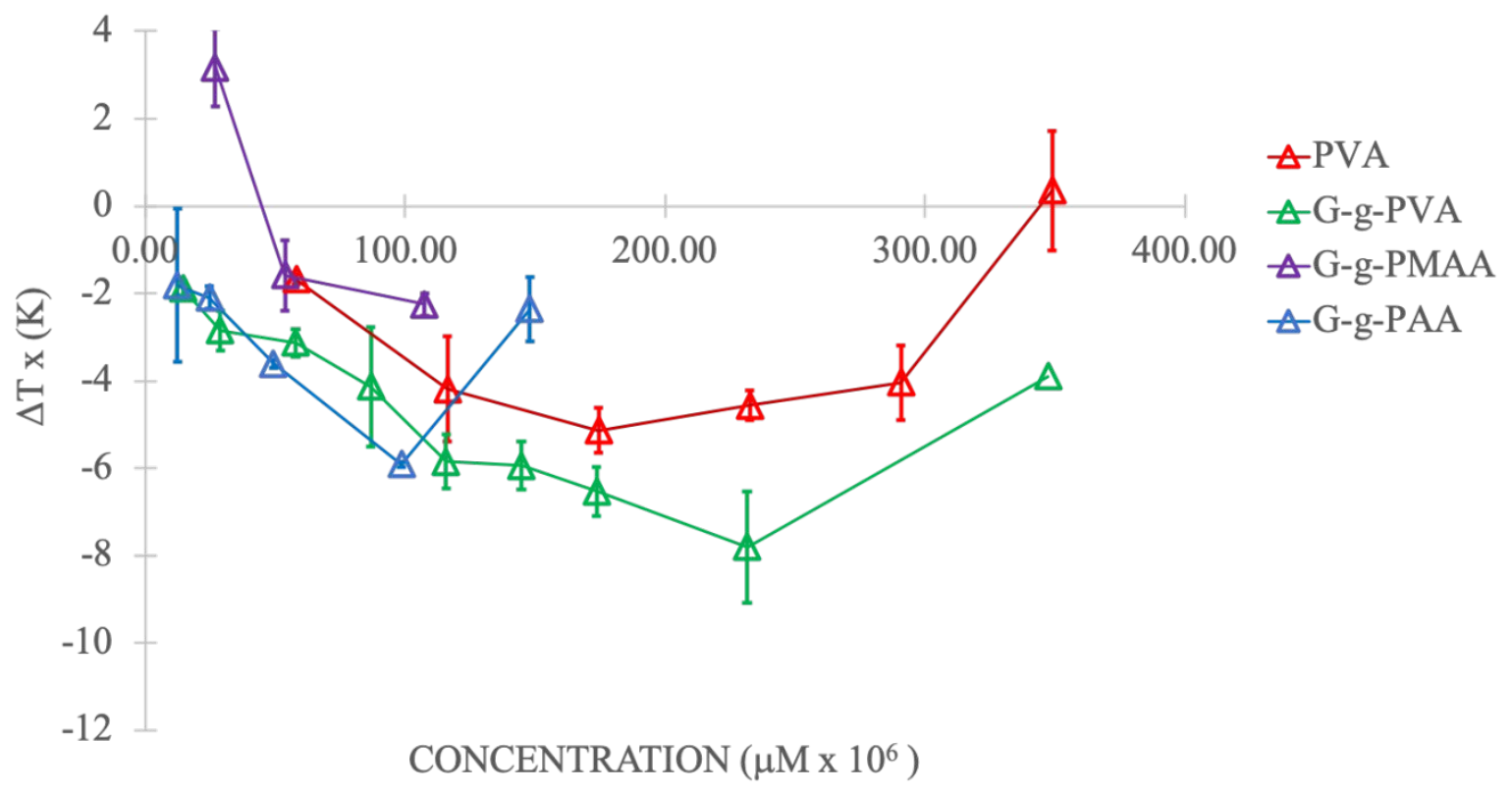

Figure S6. Ice nucleation inhibition data from Figure 1 (in the main text) versus molar concentration 


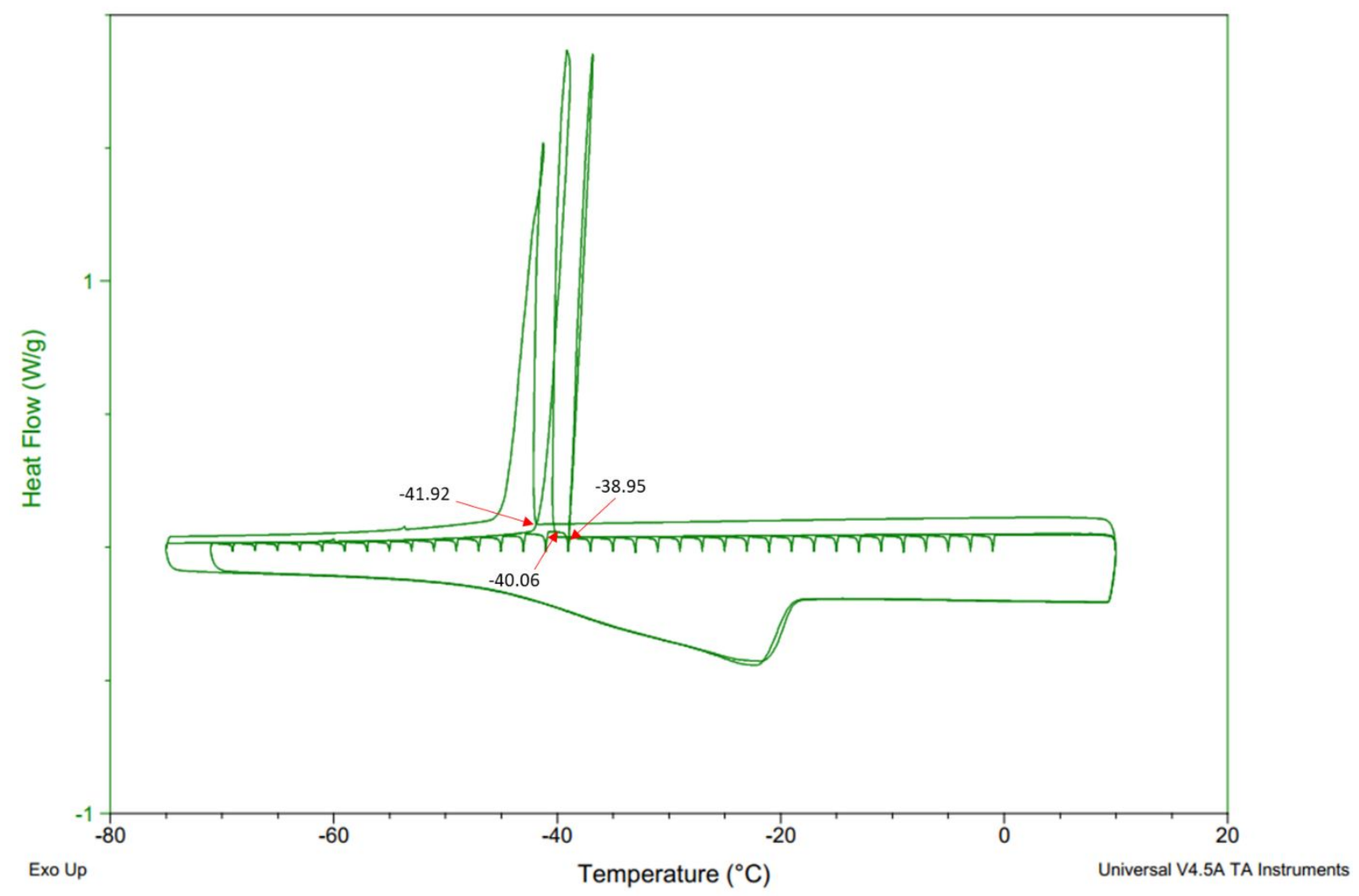

Figure S7. Impact of cooling rate on INI for ethanol. Arrows indicate the supercooling onset of exotherm for ethanol when employing a $2{ }^{\circ} \mathrm{C} /$ min linear cooling rate $\left(-41.92{ }^{\circ} \mathrm{C}\right), 1{ }^{\circ} \mathrm{C} /$ min linear cooling rate $\left(-40.06{ }^{\circ} \mathrm{C}\right)$, and a $1{ }^{\circ} \mathrm{C} / \mathrm{min}$ "stepwise" cooling rate/process with a 10 -minute isothermal hold between each $1{ }^{\circ} \mathrm{C}$ incremental step $\left(-38.95^{\circ} \mathrm{C}\right)$ 


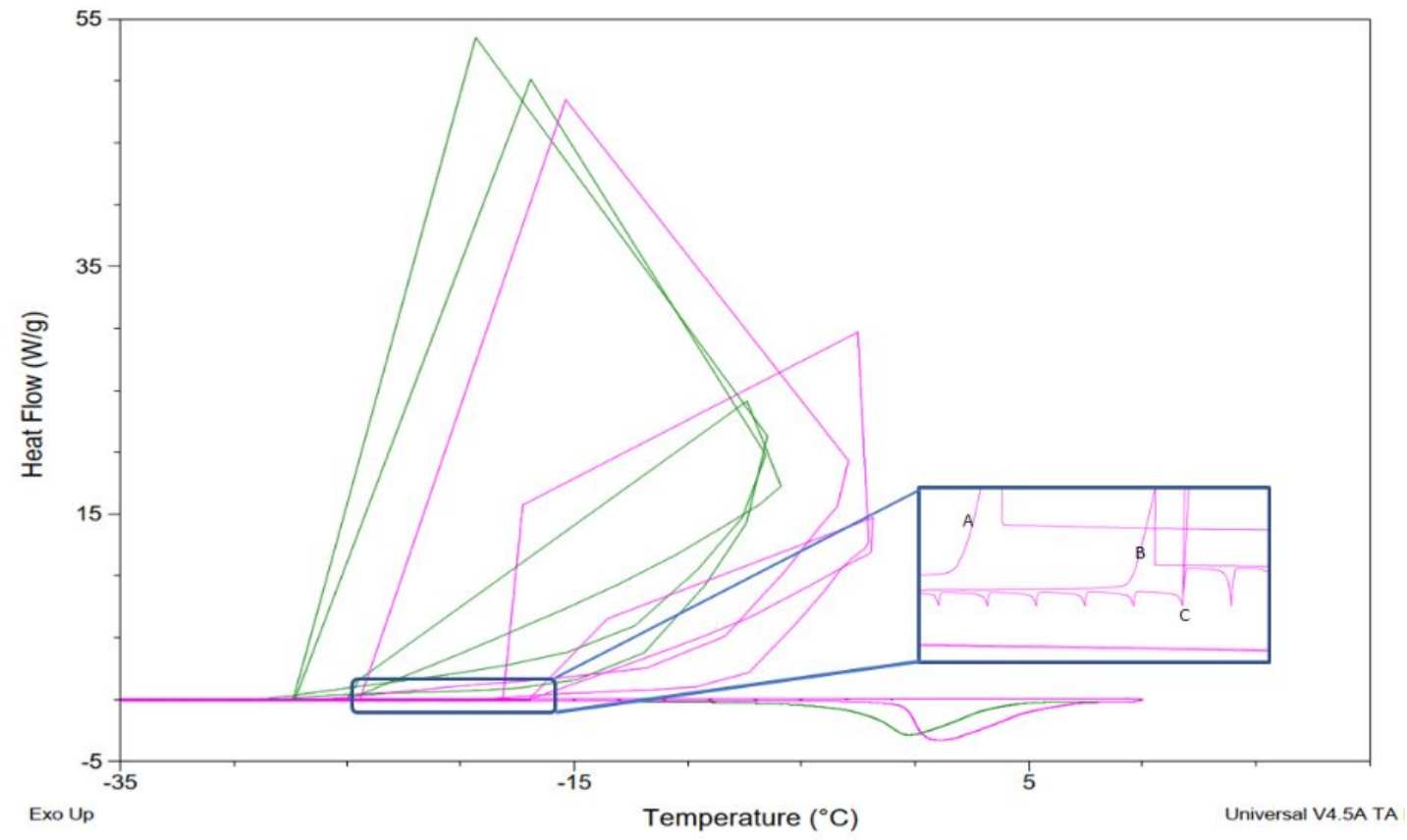

Figure S8. Impact of cooling rate on INI for PVA (pink) and G-g-PVA (green). Inset of the supercooling onset exotherms for PVA at A) $2{ }^{\circ} \mathrm{C} / \mathrm{min}$ linear cooling rate $\left(-24.42{ }^{\circ} \mathrm{C}\right)$, B) 1 ${ }^{\circ} \mathrm{C} / \mathrm{min}$ linear cooling rate $\left(-18.17{ }^{\circ} \mathrm{C}\right)$, and $\left.\mathrm{C}\right) 1^{\circ} \mathrm{C} / \mathrm{min}$ "stepwise" cooling rate with 10 -minute isothermal hold between each $1^{\circ} \mathrm{C}$ step $\left(-16.86^{\circ} \mathrm{C}\right)$. The same respective sets of exotherm versus cooling rate/process for G-g-PVA (in green profiles) are $-27.36{ }^{\circ} \mathrm{C},-27.26{ }^{\circ} \mathrm{C}$, and $-25.01{ }^{\circ} \mathrm{C}$

Table S1. Heterogeneous ice nucleation temperature variation with cooling rate for the polymer solutions (25.0 mg. $\left.\mathrm{ml}^{-1}\right)$. Continuous linear cooling with $1{ }^{\circ} \mathrm{C} / \mathrm{min}$ cooling rate $[\mathrm{Cl}]$, Continuous linear cooling with $2{ }^{\circ} \mathrm{C} / \mathrm{min}$ cooling rate. [C2], Stepwise-cooling method with 10 -minute isothermal hold between each $1^{\circ} \mathrm{C}$ step $[C S]$.

\begin{tabular}{cccc|}
\hline Sample & $\mathbf{T}_{\mathbf{N}}(\mathbf{C})[C 2]$ & $\mathbf{T}_{\mathbf{N}}(\mathbf{C})[C 1]$ & $\mathbf{T}_{\mathbf{N}}(\mathbf{C})[C S]$ \\
\hline PVA & -24.42 & -18.17 & -16.86 \\
\hline G-g-PAA & -22.23 & -19.56 & -19.01 \\
\hline G-g-PVA & -27.36 & -27.26 & -25.01 \\
\hline G-g-PMAA & -18.58 & -15.59 & -15.00 \\
\hline G-g-PIPOH & -23.61 & -23.40 & -22.72 \\
\hline
\end{tabular}




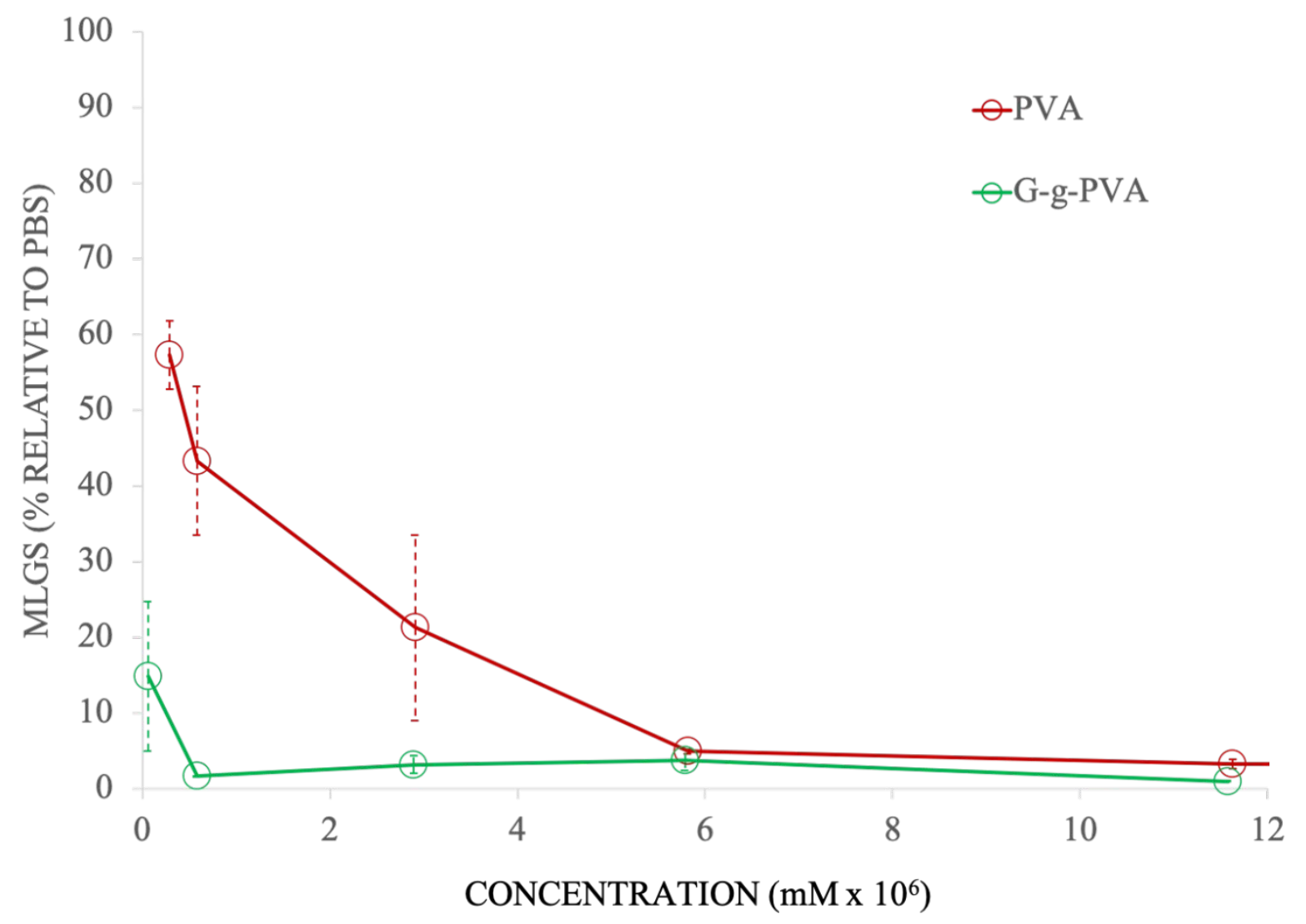

Figure S9. Ice recrystallization inhibition data from Figure 3 (in the main text) versus molar concentration 


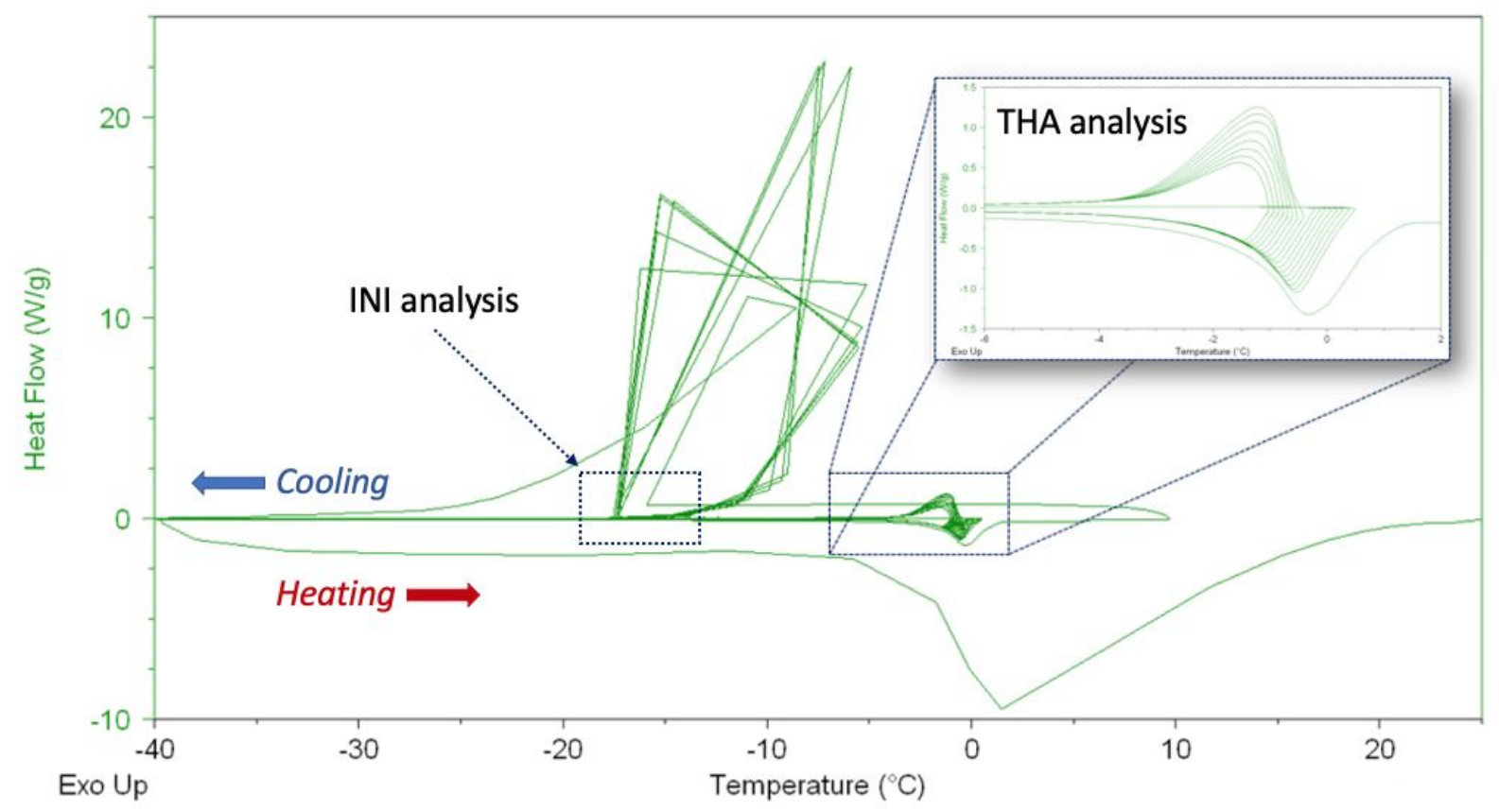

Figure S10. Full differential scanning calorimetry (DSC) method output for analysis of THA. Both the INI analysis and THA analysis can be performed simultaneously where the inset zoom image of the heat flow profiles shows the specific cycles relevant to the THA assay. 